NEW ZEALAND RESEARCH

\title{
Low-cost, self-paced, educational programmes increase birth satisfaction in first-time mothers
}

\author{
Anne M. Howarth ${ }^{A, B} P h D \cdot$ Nicola R. Swain ${ }^{B} P h D$
}

${ }^{\text {A }}$ Corresponding Author: nicola. swain@otago.ac.nz

${ }^{\text {B Department }}$ of Psychological Medicine, Dunedin School of Medicine

\begin{abstract}
Introduction: Birth satisfaction is an important aspect of giving birth. It is a subjective way to quantify how the experience went for new mothers.

Aim: This research aimed to assess whether either of two self-directed educational programmes could improve birth satisfaction in New Zealand first-time mothers.

Method: One hundred and eighty-two women were recruited and randomly assigned to a skills preparation group, a birth stories booklet group, or a treatment as usual (TAU) group.

Findings: One hundred and thirty-seven women completed the three questionnaires relevant for this report (a 75\% retention rate). Birth satisfaction was measured soon after birth. It was found that women who received either of the birth preparation programmes (skills or birth stories booklet) had significantly higher birth satisfaction scores. A post-hoc analysis found that, irrespective of programme, having either an induction or a caesarean birth had a negative effect on birth satisfaction, while having birth expectations met had a positive impact on birth satisfaction.

Conclusions: Increased preparation for childbirth may be important for birth satisfaction; both induction and caesarean section reduce satisfaction; and expectations around birth might be managed to improve satisfaction. This study found evidence that simple low-cost programmes can improve birth satisfaction.
\end{abstract}

Keywords: childbirth, childbirth preparation, birth stories, labour, satisfaction

\section{INTRODUCTION}

Birth satisfaction is a subjective evaluation made by women who have given birth. It encompasses many aspects of their experiences. Women may be evaluating their own coping, the care received and a general reconstruction of the experience. This may be accurate or less accurate, but it does reflect their perceptions of their experiences at the time (Proctor, Hollins Martin, Larkin, \& Martin, 2017). Women have hopes and expectations of what their birthing experiences will be like, and these expectations affect how they anticipate and approach the births of their children (Ayers \& Pickering, 2005; Gibbins \& Thomson, 2001). Satisfaction with birth has long-term influences on the future health of the woman and her family (Maimburg, Væth, \& Dahlen, 2016).

Various phenomena have been found to contribute towards experiencing a sense of birth satisfaction. Howarth, Swain and Treharne (2011a, 2011b, 2013) reported the following themes as linked to positive birth satisfaction in mothers: taking personal responsibility (Howarth et al., 2011a); important relationships during pregnancy and birth (Howarth et al., 2011b); and the availability of a safety net (Howarth et al., 2013). Another group of women who all had positive birth experiences also endorsed a sense of safety, personal control and trusting relationships (Karlström, Nystedt, \& Hildingsson, 2015). Similarly, Aune et al. (2015) concluded that the two most important things leading to increased birth satisfaction were a safe environment and emotional strength.
In a qualitative study using grounded theory methodology, Koehn (2008) reported that women were aware that childbirth is unpredictable and that childbirth education helped them to prepare and be ready. Preparing for childbirth is important. Another study of childbirth preparation randomly assigned 170 women to either a 10-session education course or treatment as usual. They found a dramatic lowering of interventions, including caesareans, among those who had been assigned educational sessions (Karimi, Kazemi, Masoumi, Shobeiri, \& Roshanaei, 2016). Childbirth classes have been shown to reduce fear and increase the chance of normal vaginal birth (Najafi, Abouzari-Gazafroodi, Jafarzadeh-Kenarsari, Rahnama, \& Gholami Chaboki, 2016). The resulting childbirth self-efficacy, the belief that women have all the skills needed to manage the childbirth process, has been found to enhance birth satisfaction (Berentson-Shaw, Scott, \& Jose, 2009).

Women reported that childbirth experiences were better when there were fewer medical interventions; this included both home births and hospital births (Handelzalts, Zacks, \& Levy, 2016). Risk factors identified by Waldenström, Hildingsson, Rubertsson and Rådestad (2004) for poor birth satisfaction included unexpected medical problems and interventions such as induction and emergency caesarean section. Inductions were also seen as a risk factor for decreased birth satisfaction by Martin and Fleming (2011) and Svärdby, Nordström and Sellström (2007).

Unexpected and emergency caesarean births may decrease childbirth satisfaction and may increase the risk of negative psychosocial 
outcomes for women. One of the reasons found for these poor outcomes was that a caesarean violated birth expectations (Lobel $\&$ DeLuca, 2007). One study suggested that women who had a planned caesarean had greater childbirth satisfaction than those who planned a vaginal delivery but experienced an emergency caesarean (Blomquist, Quiroz, MacMillan, McCullough, \& Handa, 2011). The explanation given for differences was that the lower satisfaction came from the fact these caesareans were unplanned. Consequently, Carquillat, Boulvain and Guittier (2016) caution that type of birth may not be the important factor and that a more nuanced view of the psychological and emotional factors needs to be considered.

Women may be dissatisfied with medical procedures for which they felt ill prepared. As well as dissatisfaction, some women may also experience post-traumatic stress disorder after a difficult childbirth experience (Ayers, Wright, \& Wells, 2007; Soderquist, Wijma, \& Wijma, 2002). In a large longitudinal cohort study involving 2,541 Swedish women, Waldenström et al. (2004) examined satisfaction with experiences of labour and birth. They reported that seven percent of women indicated that they had had a negative birth experience.

Unmet childbirth outcome expectations, especially if combined with a difficult postpartum recovery, also created potential risk factors for decreased birth satisfaction which may impact on the development of maternal identity (Nelson, 2003). Because she may be left confused as to why her birth experience went wrong, a new mother may feel she was at fault in some way, that she failed, and that she may continue to fail in her role as mother (Miller, 2007). However, when the outcome matches a woman's expectations of childbirth, her satisfaction with her birth experience is heightened (Goodman, Mackey, \& Tavakoli 2004). At the time of our trial, most pregnant women can access free childbirth education courses, which are offered in the third trimester, are a minimum of 12 hours total duration, and cover access to maternity services, pregnancy care, labour and birth care, and care following birth (Dwyer, 2009). It was by reported by Dwyer (2009) that 80 percent of New Zealand first-time pregnant women attended a childbirth education course and that they said the course prepared them for birth. More recently, the latest New Zealand Maternity Consumer Survey from 2014 states "Twothirds of first-time mothers (64 percent) went to antenatal classes" (Ministry of Health, 2015, p.28).

This study aimed to test the hypothesis that birth satisfaction can be enhanced through the use of educational material supplied to the mother. In this case we used either a skills-based preparation package, or a birth stories booklet. Both these programmes are low-cost, self-paced, independent and not taught as a part of the standard antenatal education programme.

\section{METHOD}

\section{Design}

This study was a randomised controlled trial (RCT) that compared two educational programmes for childbirth preparation (The Pink Kit Method for Birthing Better ${ }^{\circledR}$, or birth stories) with standard care for first-time New Zealand mothers.

The RCT examined the two programmes' effectiveness for a number of different outcomes, one of which was birth satisfaction. Other outcomes examined include birth self-efficacy (Howarth \& Swain, 2019) and labour pain as well as midwife stress and fathers' birth experiences (Howarth, Scott, \& Swain, 2017a, 2017b). This report is concerned with the impact of childbirth skills preparation, a birth stories booklet, and other factors thought to impact on birth satisfaction for first-time mothers

A number of variables were measured as part of the larger study. The following measures were considered as confounders of the effect of the two programmes on childbirth satisfaction: depression before birth as measured by the Edinburgh Postnatal Depression Score (EPDS), family life satisfaction before birth, childbirth self-efficacy, pregnancy anxiety, medical interventions, and expectations of labour and birth.

This project was reviewed and approved by the Lower South Regional Ethics Committee (Reference Number: LRS/10/11/052). It is registered as a clinical trial: ACTRN12616001545459.

\section{Eligibility of participants}

The study inclusion parameters were: first-time pregnant women, residing in New Zealand, aged 18 years or over and 42 years or less at the time of enrolment (these age limits were applied because younger and older women often have specialised healthcare and specific psychological and social needs that were beyond the scope of this research project), English speaking, living in a relationship with the father, and less than 24 weeks pregnant. Women who met these criteria were invited to participate. Being married or in a civil union was not a requirement, but living with the father was needed for analysis in a related study of fathers' experiences.

\section{Recruitment}

Women were recruited through advertisements, using both traditional (e.g., posters, flyers, magazine and newspaper advertisements - local and national) and online (dedicated website, Facebook postings and advertisements, posting details on relevant sites with permission from the owners) methods during May, 2011 to April, 2013. Posters and flyers were posted to midwifery practices, libraries, hospitals, and universities throughout New Zealand.

\section{Procedure}

Once recruited, women were asked to complete a baseline questionnaire and could choose either paper documentation or online documentation using Google Docs. Online documents were accessed by participants through the website (enrolment documents including information sheet, consent form and demographics) and through links emailed to participants at the appropriate times by the primary researcher (questionnaires). Paper documents were posted on request to participants (enrolment documents including information sheet, consent form and demographics). Other documents, including questionnaires, were posted to participants at the appropriate times. The women completed demographics information on enrolment in the study prior to 22 weeks' gestation.

After completing the baseline questionnaire at 24 weeks' gestation, participants were randomly assigned into one of three groups: the Skills Group; the Birth Stories Group; and the Treatment As Usual (TAU) Group. The randomisation process was conducted using online randomisation software, and undertaken by a colleague not involved in the study in any other way.

Participants in the Skills Group were issued with the anonymised version of The Pink Kit Method for Birthing Better ${ }^{\circledR}$, and were to work through the programme between 24 and 36 weeks' gestation. Participants in the Birth Stories Group were issued with the birth stories booklet at 24 weeks' gestation and asked to read through it any time before birth. The TAU Group received no additional material.

A second questionnaire was completed at 36 weeks' gestation and a third as soon after birth as the woman felt able. 


\section{Skills Group}

The programme was an anonymised version of The Pink Kit Method for Birthing Better ${ }^{\circledR}$, a commercially available, self-paced, multi-media, skills-based, childbirth preparation programme available on the internet (Common Knowledge Trust, 2001). Permission was requested and granted by the developers of the programme to remove all identifying material. The information and structure of the programme were not altered.

The version of the programme used (2010) contained four books, two audio CDs and one video DVD. The four books had the following content: breath, language and touch skills; teamwork for managing skills; rationalisation for basic skills applicable for every birth; and extra skills for specific situations. The DVD demonstrated specific practical skills to manage the birth process and keep the birth canal relaxed and open. Examples of exercises included directed breathing, mapping the pelvis, teamwork, deep touch relaxation, cervical relaxation and hip lift. The two CDs focussed on how to prepare the birth passage and skills for each phase of a contraction.

The course contained around 40 hours of content. It was recommended that study commence at 24 weeks' gestation, and it was suggested that 5-15 minutes learning about and practising these skills every day or two would provide women with the skills required. As the programme used a self-teach methodology, the women were responsible for their own time commitment and learning. Women indicated that on average they completed at least 50 percent of the programme.

\section{Birth Stories Booklet Group}

A 58-page birth stories book was compiled by the primary researcher $(\mathrm{AH})$ to include examples of births that participants may experience. It included personal stories divided into chapters. The chapters were: home births, water births at home and hospital, natural births in hospital, hospital births with induction and/or pain management, premature and multiple births, pregnancy and birth complications, forceps and ventouse births in hospital, and unexpected caesarean births in hospital.

Birth stories were chosen as a programme because women in a previous study had indicated a desire to read more birth stories during their pregnancies (contact authors for a copy of the birth stories booklet).

\section{Treatment As Usual Group}

Participants in this group were asked to proceed as usual.

\section{All groups}

All groups were asked to continue with whatever activities they had previously planned and to participate in any education or preparation for birth that they wanted to. Post birth, all groups were asked if they had used the Pink Kit Method for Birthing Better $^{\circledR}$, as it is commercially available. Those participants who answered in the affirmative and who were not in the Skills Group were excluded from the analysis. Those issued the birth stories booklet were asked not to share it for the duration of the trial.

\section{Measures}

Birth satisfaction was measured using the Mackey Childbirth Satisfaction Rating Scale (Goodman et al., 2004) New Zealand Adaptation. The 34-item scale contains questions related to the behaviours of self, partner, baby, nurse (midwife) and physicians. A further six questions relate to expectations. Items 1 to 34 are scored on a five-point Likert scale $(1=$ very dissatisfied; $5=$ very satisfied). The six items measuring expectations are scored on a four-point Likert scale. Scores can range from 38 to 186; the higher the score, the greater the birth satisfaction.
Differing systems (American/New Zealand) created issues when using Mackey Childbirth Satisfaction Rating Scale (Goodman et al., 2004). For example, many women do not require the services of a physician/obstetrician, so a sixth scoring column entitled N/A was added. Additionally, because the scale was developed for women giving birth in the American maternity system, consideration was also given to differing terminology; for example, the term "nurse" was altered to "midwife" (Figure 1). Permission was requested from, and given by, Mackey to use this scale and make these adaptations. Overall reliability was excellent $(\partial=0.93$; Goodman et al., 2004). In the current study Cronbach's alpha was $\partial=0.90$.

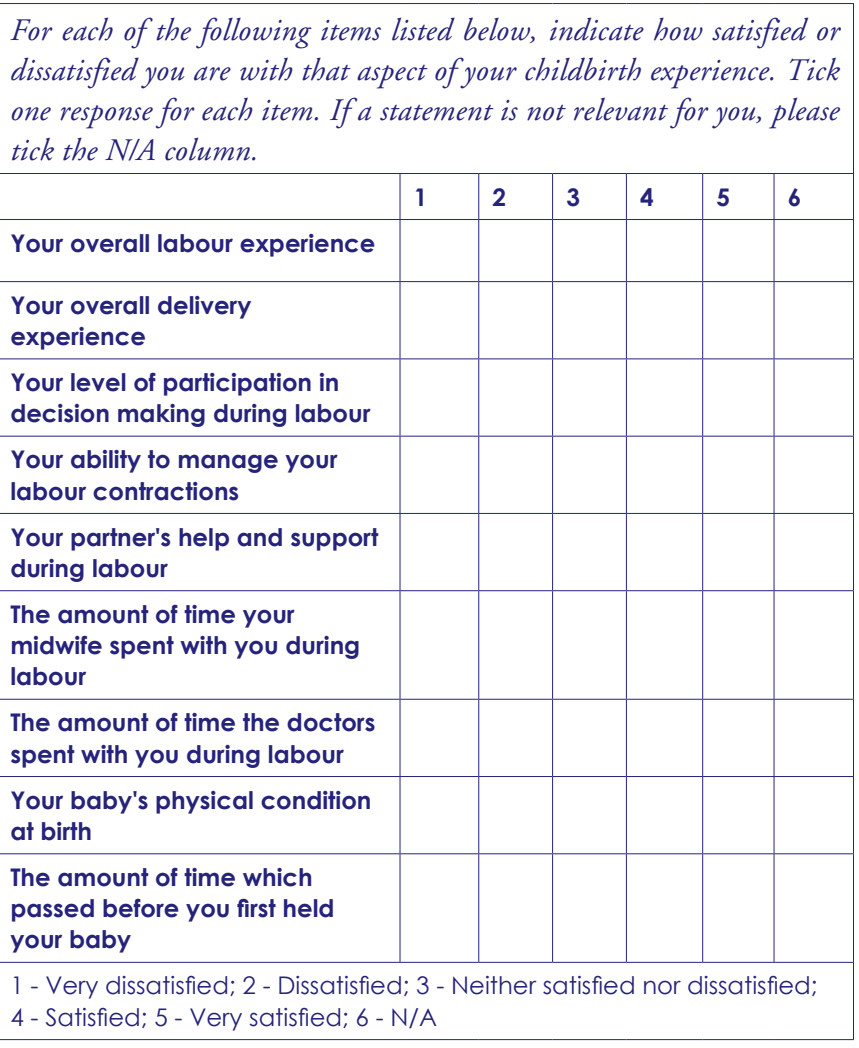

Figure 1. Examples of questions from the Mackey Childbirth Satisfaction Rating Scale (Goodman et al., 2004) New Zealand Adaptation

\section{Data analysis}

The trial examined the hypothesis that additional childbirth education would result in greater birth satisfaction for women. A one-way ANOVA examined for differences between the three groups using a per protocol sample of 137 women. A post-hoc analysis was then conducted on the full set of data combined. Twostep hierarchical multiple regression (sequential regression) was used to identify models of predictive variables for birth satisfaction. Model 1 corrected for the programme used in the trial.

\section{FINDINGS}

Of the 199 women assessed for eligibility, 182 women were enrolled. One hundred and thirty-seven women completed the three questionnaires (at 24 and 36 weeks' gestation and post birth) relevant for this report, a $75 \%$ retention rate.

At the time of recruitment the mean age of the women was 29.2 years, with a range of 19 to 41 years. Table 1 demonstrates that there were no significant differences in age between groups ( $\mathrm{F}$ $[2,134]=0.022, \mathrm{p}=0.978)$. 
Table 1. Mean age and range of ages of participants by group ( $n=137$ ) Women's age

$\begin{array}{llll}\text { Group } & \text { Mean } & \text { Minimum } & \text { Maximum } \\ \text { Skills Group } & 29.2 & 19 & 41 \\ \begin{array}{l}\text { Birth Stories } \\ \text { Group }\end{array} & 29.0 & 19 & 38 \\ \text { TAU Group } & 29.2 & 20 & 38\end{array}$

Women were predominantly well-educated career women of NZ European ethnicity who were working full-time at the time of recruitment. The majority of participants were married, owned their own homes, and earned in the higher income bracket. There were significant differences between groups for work status, with fewer women in the Skills Group working full-time. However, regression analysis indicated this did not impact on the outcome birth satisfaction (Table 2).

\begin{tabular}{|c|c|c|c|c|}
\hline & Demographic & Skills & Birth Stories & TAU \\
\hline \multirow{2}{*}{$\begin{array}{l}\text { Marital } \\
\text { status }\end{array}$} & Married & 60.5 & 70.8 & 58.8 \\
\hline & De facto' & 39.5 & 29.2 & 41.2 \\
\hline \multirow{2}{*}{$\begin{array}{l}\text { Home } \\
\text { ownership }\end{array}$} & Own home & 60.5 & 54.3 & 62.7 \\
\hline & $\begin{array}{l}\text { Does not own } \\
\text { home }\end{array}$ & 39.5 & 45.7 & 37.3 \\
\hline \multirow{5}{*}{$\begin{array}{l}\text { Tertiary } \\
\text { education }\end{array}$} & None & 18.4 & 18.8 & 10.0 \\
\hline & Tertiary cert./dipl. & 13.2 & 25.0 & 26.0 \\
\hline & Bachelor's degree & 39.5 & 27.1 & 38.0 \\
\hline & Post-grad cert./dipl. & 13.2 & 12.5 & 16.0 \\
\hline & $\begin{array}{l}\text { Master's or PhD } \\
\text { degree }\end{array}$ & 15.8 & 16.7 & 10.0 \\
\hline \multirow[t]{4}{*}{ Work status } & Working full-time & 52.6 & 70.8 & $78.4^{*}$ \\
\hline & Working part-time & 13.2 & 8.3 & 11.8 \\
\hline & Student & 18.4 & 6.3 & 9.8 \\
\hline & At home & 15.8 & 14.6 & 0.0 \\
\hline \multirow{4}{*}{$\begin{array}{l}\text { Family } \\
\text { income }\end{array}$} & Up to $\$ 25,000$ & 5.3 & 0.0 & 3.9 \\
\hline & $\$ 25,001-\$ 50,000$ & 21.1 & 6.3 & 7.8 \\
\hline & Over $\$ 50,001$ & 71.1 & 89.6 & 86.3 \\
\hline & Don't know & 2.6 & 4.2 & 2.0 \\
\hline \multirow[t]{5}{*}{ Ethnicity ${ }^{2}$} & Māori & 7.9 & 8.3 & 3.9 \\
\hline & NZ European & 97.4 & 93.8 & 98.0 \\
\hline & Asian & 2.6 & 2.1 & 2.0 \\
\hline & Pacific peoples & 2.6 & 2.1 & 0.0 \\
\hline & MELAA ${ }^{3}$ & 2.6 & 4.2 & 0.0 \\
\hline \multicolumn{5}{|l|}{$* p<.05$} \\
\hline \multicolumn{5}{|c|}{ 'Living together in a relationship but not married } \\
\hline \multicolumn{5}{|c|}{${ }^{2}$ People may identify with more than one ethnicity } \\
\hline \multicolumn{5}{|c|}{${ }^{3}$ Middle Eastern/Latin American/African } \\
\hline
\end{tabular}

A one-way ANOVA found that group differences in birth satisfaction were statistically significant (Table 3).

The Tukey Honest Significance post-hoc test was used to determine if the statistically significant ANOVA findings for birth satisfaction for mothers indicated higher scores for any particular group (Table 4).

\begin{tabular}{|c|c|c|c|c|c|}
\hline & $\mathrm{n}$ & Mean & $\begin{array}{l}\text { Std. } \\
\text { deviation }\end{array}$ & F value & Significance \\
\hline Skills & 38 & 159.35 & 20.685 & 6.457 & $.002^{* *}$ \\
\hline Birth Stories & 48 & 160.46 & 17.326 & & \\
\hline TAU & 51 & 146.53 & 24.616 & & \\
\hline
\end{tabular}

\begin{tabular}{|c|c|c|c|}
\hline \multicolumn{4}{|l|}{${ }^{* *} p<.01$} \\
\hline Measure & Mean difference & Std. error & Significance \\
\hline \multicolumn{4}{|c|}{ Birth satisfaction } \\
\hline Skills-Stories & -1.106 & 4.604 & .969 \\
\hline Skills-TAU & 12.819 & 4.544 & $.015^{*}$ \\
\hline Stories-TAU & 13.925 & 4.264 & $.004^{* *}$ \\
\hline
\end{tabular}

${ }^{*} \mathrm{p}<0.05,{ }^{*} \mathrm{p}<0.01$

The Tukey post-hoc test revealed that there was no significant difference between the Skills Group and the Birth Stories Group for birth satisfaction for participants. However, women in both the Skills Group and the Birth Stories Group experienced significantly higher satisfaction with their birth experience than the women in the TAU Group.

An exploratory post-hoc analysis was conducted of birth satisfaction (Table 5). Two-step, hierarchical, multiple regression analysis was used. Step 1 accounted for the group assigned in the trial.

\begin{tabular}{|c|c|c|c|c|c|c|}
\hline \multirow[t]{2}{*}{ Predictor } & B & $\begin{array}{l}\text { Std. } \\
\text { error }\end{array}$ & Beta & $t$ & Sig. & $\begin{array}{l}\text { Adjusted } \\
\mathbf{R}^{2}\end{array}$ \\
\hline & & & & & & .285 \\
\hline $\begin{array}{l}\text { Depression } \\
\text { (before birth) } \\
\text { (EPDS) }\end{array}$ & -.246 & .434 & -.051 & -.566 & .573 & \\
\hline $\begin{array}{l}\text { Family life } \\
\text { satisfaction } \\
\text { (before birth) }\end{array}$ & -.142 & .147 & -.091 & -.969 & .335 & \\
\hline $\begin{array}{l}\text { Childbirth } \\
\text { self-efficacy }\end{array}$ & .017 & .042 & .034 & .407 & .684 & \\
\hline $\begin{array}{l}\text { Pregnancy } \\
\text { anxiety }\end{array}$ & -.532 & .368 & -.119 & -1.444 & .151 & \\
\hline $\begin{array}{l}\text { Medical } \\
\text { intervention }\end{array}$ & 8.177 & 4.380 & .165 & 1.867 & .064 & \\
\hline $\begin{array}{l}\text { Induction of } \\
\text { labour }\end{array}$ & -10.302 & 4.010 & -.219 & -2.569 & $.011^{*}$ & \\
\hline $\begin{array}{l}\text { Caesarean } \\
\text { birth }\end{array}$ & -13.232 & 3.994 & -.276 & -3.313 & $.001^{* *}$ & \\
\hline $\begin{array}{l}\text { Labour } \\
\text { expectations } \\
\text { met }\end{array}$ & 4.173 & 4.073 & .088 & 1.025 & .307 & \\
\hline $\begin{array}{l}\text { Birth } \\
\text { expectations } \\
\text { met }\end{array}$ & 8.808 & 4.212 & .184 & 2.091 & $.039 *$ & \\
\hline
\end{tabular}

Introducing the covariates, induction and caesarean, was associated with lower birth satisfaction and birth expectations (positive expectation met was associated with higher birth satisfaction), increased our understanding of what contributes towards higher birth satisfaction by a moderate statistically significant amount. Medical intervention experienced had a modest negative effect approaching statistical significance. 


\section{DISCUSSION}

This study aimed to identify whether birth satisfaction can be enhanced through the use of educational material supplied to the woman. We found that the provision of either one of two childbirth preparation programmes (a skills-based, multimedia, childbirth preparation course or a compilation of birth stories) increased birth satisfaction. This finding may relate to an improved understanding of how the woman can manage her labour and birth. It may also relate to improved coping skills which may enhance the possibility for women having their first baby to increase birth satisfaction. It could be that either programme helped women form more realistic expectations of labour and birth. Additionally, using a post-hoc test of birth factors, while controlling for group, found the greatest influences on childbirth satisfaction were inductions, caesareans and childbirth expectations.

The mechanism by which a skills programme or reading birth stories increases birth satisfaction remains unknown. We speculate an increase in childbirth skills may have had a direct effect on childbirth satisfaction, while perhaps the birth stories booklet provided role models for the first-time mother. In another study it was found that reading these birth stories had not resulted in an increase in childbirth self-efficacy for mothers (Howarth \& Swain, 2019); it may be that women had absorbed information that related to expectations. Previous research suggests expectations are one of the important pathways to childbirth satisfaction (Goodman et al., 2004). In New Zealand most first-time pregnant women attend antenatal classes (Dwyer, 2009). Although these classes are both important and helpful, it would appear that more can be done to prepare women for a satisfying childbirth experience. Increasing this satisfaction can have long-term health and wellbeing benefits, for both a woman and her family (Maimburg et al., 2016).

Despite the fact that medical interventions may save lives, unexpected medical procedures can be challenging experiences for women and can result in them perceiving their birthing experiences more negatively (Martin \& Fleming, 2011; Svärdby et al., 2007; Waldenström et al., 2004). Post-hoc analysis suggested that inductions and caesareans decreased birth satisfaction for participants, which is supported by other studies (Lobel \& DeLuca, 2007; Martin \& Fleming, 2011; Svärdby et al., 2007; Waldenström et al., 2004). This may be important information for women and for providers to consider when making decisions about interventions. Goodman et al. (2004) found that when the experience of childbirth is better than expected, birth satisfaction is enhanced. This suggests that it may not be the caesarean or intervention per se that causes lower satisfaction but other factors associated with the caesarean (Carquillat et al., 2016).

\section{LIMITATIONS AND STRENGTHS}

The demographics of the women taking part in this project were not nationally representative. It happened that participants were principally recruited from well-educated, professional people who were NZ European, employed and in the higher income bracket. Few first-time mothers from the lower socio-economic sectors of New Zealand society engaged with the study. Because of this, generalisability of results to the whole New Zealand population of first-time mothers cannot be assured.

The strengths of the study include randomisation of the participants. By randomly assigning participants to one of three groups, the trial minimised allocation bias in treatment assignment by keeping other unknown variables constant. Testing confirmed that groups were similar in terms of demographic characteristics.
Baseline testing also reinforced that randomisation had been successful. This added to the confidence that differences between experimental groups at outcome would reflect the impact of the programme.

\section{CONCLUSION}

Birth satisfaction is an important evaluation for women. Both skills-based childbirth preparation and a birth stories package appear to have had a positive effect on birth satisfaction. This is in the context where pregnant women can also access formal childbirth education. Teaching women skills for, in conjunction with giving them information about, labour and birth would appear to have the potential to significantly enhance a woman's childbirth satisfaction. As well, given the simplicity of providing a book of birth stories, this could be a viable option for increasing birth satisfaction for women. The impact of expectations could be seen in this research and this is perhaps the moderator for birth preparations to increase birth satisfaction. Regardless of the nature and degree of preparation, some birth interventions, such as caesarean section and induction of labour, may have a negative effect on birth satisfaction. This study provides evidence that simple low-cost programmes can improve first-time pregnant women's birth satisfaction. These findings should be replicated with further research using examples of self-paced education to establish whether the two programmes in the present research were contributing, or a variety of educational approaches are helpful. The implication for practice is that midwives could provide or recommend at home self-guided birth preparation material, such as birth stories, to increase first-time mothers' birth satisfaction.

\section{Key points}

- A first-time mother and her family benefit if she feels positive and satisfied about her birth experience.

- $\quad$ Researchers tested if two specific birth preparation programmes would help improve a woman's birth satisfaction. Both were self-paced and low cost.

- Women who used either programme were more positive before the birth and more satisfied with their birth experience afterwards.

\section{ACKNOWLEDGEMENTS AND CONFLICT OF INTEREST DISCLOSURE}

Preparation of this paper received the support of the Graduate Research Committee, by means of the University of Otago Postgraduate Publishing Bursary (Doctoral).

The authors declare that there are no conflicts of interest.

\section{REFERENCES}

Aune, I., Torvik, H.M., Selboe, S.T., Skogås, A.K., Persen, J., \& Dahlberg, U. (2015). Promoting a normal birth and a positive birth experience-Norwegian women's perspectives. Midwifery, 31(7), $721-727$ 
Ayers, S., \& Pickering, A.D. (2005). Women's expectations and experience of birth. Psychology \& Health, 20(1), 79-92.

Ayers, S., Wright, D.B., \& Wells, N. (2007). Symptoms of posttraumatic stress disorder in couples after birth: Association with couple's relationship and parent-baby bond. Journal of Reproductive and Infant Psychology, 25(1), 40-50.

Berentson-Shaw, J., Scott, K.M., \& Jose, P.E. (2009). Do selfefficacy beliefs predict the primiparous labour and birth experience? A longitudinal study. Journal of Reproductive and Infant Psychology, 27(4), 357-373.

Blomquist, J.L., Quiroz, L.H., MacMillan, D., McCullough, A., \& Handa, V.L. (2011). Mothers' satisfaction with planned vaginal and planned cesarean birth. American Journal of Perinatology, 28(5), 383-388. Carquillat, P., Boulvain, M., \& Guittier, M.J. (2016). How does delivery method influence factors that contribute to women's childbirth experiences? Midwifery, 43, 21-28.

Common Knowledge Trust, (2001). The Pink Kit Method for Birthing

Better $^{\circledR}$. Retrieved from https://birthingbetter.org/.

Dwyer, S. (2009). Childbirth education: Antenatal education and transitions of maternity care in New Zealand. Retrieved from http://www. superu.govt.nz/sites/default/files/RF-Childbirth-Education.pdf

Gibbins, J., \& Thomson, A.M. (2001). Women's expectations and experiences of childbirth. Midwifery, 17(4), 302-313.

Goodman, P., Mackey, M.C., \& Tavakoli, A.S. (2004). Factors related to childbirth satisfaction. Journal of Advanced Nursing, 46(2), 212-219.

Handelzalts, J.E., Zacks, A., \& Levy, S. (2016). The association of birth model with resilience variables and birth experience: Home versus hospital birth. Midwifery, 36, 80-85

Howarth, A., Swain, N., \& Treharne, G.J. (2011a). First-time New Zealand mothers' experience of birth: Importance of relationship and support. New Zealand College of Midwives Journal, 45, 6-11.

Howarth, A.M., Swain, N., \& Treharne, G.J. (2011b). Taking personal responsibility for well-being increases birth satisfaction of first time mothers. Journal of Health Psychology, 16(8), 1221-1230.

Howarth, A., Swain, N., \& Treharne, G.J. (2013). The safety-net: what influences New Zealand first-time mothers' perceptions of safety for self and unborn child? New Zealand College of Midwives Journal, 48, 24-28.

Howarth, A.M., Scott, K.M., \& Swain, N.R. (2017a). First-time fathers' perception of their childbirth experiences. Journal of Health Psychology, January. https://doi.org/10.1177/1359105316687628

Howarth, A.M., Scott, K.M., \& Swain, N.R. (2017b). Skills-based childbirth preparation reduces stress for midwives. Midwifery, 50, 235-238.

Howarth, A.M., \& Swain, N.R. (2019). Skills-based childbirth preparation increases childbirth self-efficacy for first time mothers. Midwifery, 70, 100-105.

Karimi, S., Kazemi, F., Masoumi, S.Z., Shobeiri, F., \& Roshanaei, G. (2016). Effect of consultation and educating in preparation classes for delivery on pregnancy consequences: A randomized controlled clinical trial. Electronic Physician, 8(11), 3177-3183.

Karlström, A., Nystedt, A., \& Hildingsson, I. (2015). The meaning of a very positive birth experience: Focus groups discussions with women. BMC Pregnancy and Childbirth, 15, 251-259.

Koehn, M. (2008). Contemporary women's perceptions of childbirth education. The Journal of Perinatal Education, 17(1), 11-18.

Lobel, M., \& DeLuca, R.S. (2007). Psychosocial sequelae of cesarean delivery: review and analysis of their causes and implications. Social Science \& Medicine, 64(11), 2272-2284.

Maimburg, R.D., Væth, M., \& Dahlen, H. (2016). Women's experience of childbirth-A five year follow-up of the randomised controlled trial "Ready for Child Trial". Women and Birth, 29(5), 450-454.

Martin, C.H., \& Fleming, V. (2011). The birth satisfaction scale. International Journal of Health Care Quality Assurance, 24(2), 124-135. Miller, T. (2007). "Is this what motherhood is all about?" Weaving experiences and discourse through transition to first-time motherhood. Gender \& Society, 21, 337-358.

Ministry of Health. (2015). Maternity Consumer Survey 2014.

Wellington. Retrieved from https://www.health.govt.nz/publication/ maternity-consumer-survey-2014

Najafi, F., Abouzari-Gazafroodi, K., Jafarzadeh-Kenarsari, F., Rahnama, P., \& Gholami Chaboki, B. (2016). Relationship between attendance at childbirth preparation classes and fear of childbirth and type of delivery. Journal of Hayat, 21(4), 30-40.
Nelson, A.M. (2003). Transition to motherhood. Journal of Obstetric, Gynecologic and Neonatal Nursing, 32(4), 465-477.

Proctor, S., Hollins Martin, C.J., Larkin, D., \& Martin, C.R. (2017). Woman's experience of childbirth: Qualitative analysis from data derived from the 30-Item-Birth-Satisfaction-Scale. The Scientific Pages for Nursing, 1,(1), 10-17.

Soderquist, J., Wijma, K., \& Wijma, B. (2002). Traumatic stress after childbirth: The role of obstetric variables. Journal of Psychosomatic Obstetrics \& Gynecology, 23(1), 31-39.

Svärdby, K., Nordström, L., \& Sellström, E. (2007). Primiparas with or without oxytocin augmentation: A prospective descriptive study. Journal of Clinical Nursing, 16(1), 179-184.

Waldenström, U., Hildingsson, I., Rubertsson, C., \& Rådestad, I. (2004). A negative birth experience: prevalence and risk factors in a national sample. Birth, 31(1), 17-27.

\section{Accepted for Publication February 2019}

Howarth, A.M. \& Swain, N.R. (2019) Low-cost, self-paced, educational programmes increase birth satisfaction in first-time mothers. New Zealand College of Midwives Journal, 55, 14-19.

https://doi.org/10.12784/nzcomjnl55.2019.2.14-19 